\title{
A tribute to Jean D. Wilson (1932-2021)
}

\section{J. Larry Jameson}

Perelman School of Medicine, University of Pennsylvania, Philadelphia, Pennsylvania, USA

1 ean D. Wilson (Figure 1) passed away on June 13, 2021, at the age of 88 . He spent his entire career as a faculty member in the Department of Medicine at University of Texas Southwestern (UTSW), joining many other legendary early disciples of Donald W. Seldin (1). He rose through the ranks to be appointed the Charles Cameron Sprague Distinguished Professor of Biomedical Research in 1990, and after 51 years on the faculty, he transitioned to Professor Emeritus of Internal Medicine in 1990.

Jean's parents were both teachers in a small town in West Texas. He grew up with myriad interests and read widely. By his account, his path to medicine and science was strongly influenced by Sinclair Lewis's Arrowsmith, which tells the story of a rebellious young man from small town as he discovers a passion for rigorous experimental science. As a fifth-generation Texan, Jean exemplified the pioneer spirit by exploring previously unsolved questions in endocrinology, including unraveling the physiologic basis of male sex differentiation and mechanisms of androgen action. Jean epitomized the identity and values of a physician-scientist. As a clinician, he was among the most knowledgeable experts in endocrinology and internal medicine. His lectures were richly informative but also memorable because of his melodious, storytelling narrative style combined with rigorous logic. Though an international leader in the field of reproductive biology, he founded a diabetic foot clinic at Parkland Hospital in Dallas, reflecting his deep commitment to compassionate clinical care.

With each passing decade, Jean embraced new tools for discovery and identified new collaborators who brought distinctive skills to his projects. He is perhaps best known for demonstrating that 5 - $\alpha$-reductase, an enzyme that converts testosterone to dihydrotestosterone in selected

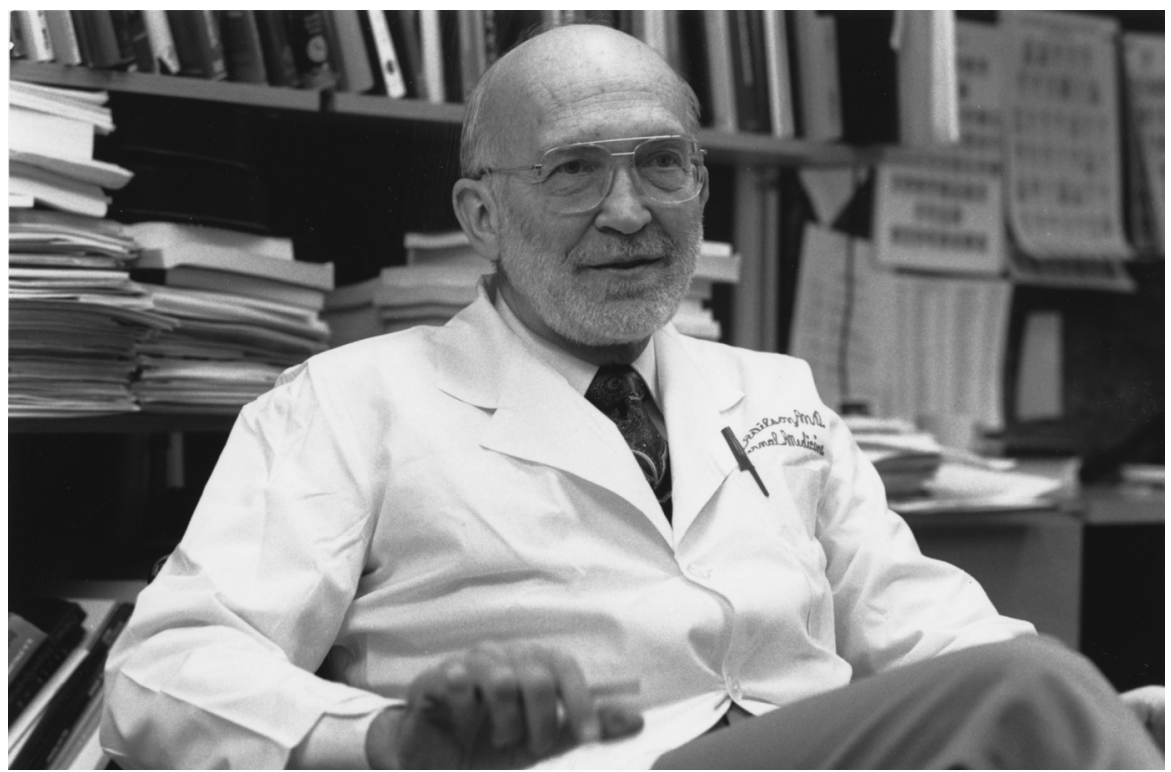

Figure 1. Jean Wilson in his academic office in 1992. Image credit: UT Southwestern.

tissues, is necessary for Wolffian duct development and male sex differentiation. In early studies seeking to understand the cellular actions of testosterone, he found that it increased protein synthesis in the male urogenital tract prior to stimulating amino acid transport, which ultimately led to the observation that testosterone initially acts at the level of gene transcription and mRNA synthesis (2). Subsequent studies using thin-layer chromatography demonstrated that the chromatin-bound radiolabeled hormone was predominantly dihydrotestosterone, a more potent derivative, generated by the enzyme 5 - $\alpha$-reductase $(3,4)$.

Jean understood the power of comparative biology and studied dozens of species. For example, he noted that benign prostatic hyperplasia occurred in humans and dogs but not lions! In a series of elegant studies, he found a high correlation between 5 - $\alpha$-reductase expression and prostate growth in humans (5) and across species, providing the foundation for the development of inhibitors, such as finasteride, to treat benign prostatic hyperplasia and male pattern baldness. His projects focused sharply on understanding the hormonal basis of phenotype, whether describing androgen insensitivity syndrome (6) or pseudovaginal perineoscrotal hypospadias (7), which he showed is caused by 5 - $\alpha$-reductase deficiency (8). Jean was masterful in using genetics to unravel molecular pathways to explain rare phenotypic features in humans, and then exploiting this knowledge to identify targets for new therapies. If this formula sounds familiar, it was deeply ingrained in the culture of UTSW, where the seminar rooms were attended regularly by faculty across departments with interests in steroid pathways and cholesterol metabolism. Case presentations frequently sparked new projects and collaborations. In these settings and others, Jean eagerly shared his skills through teaching, writing, and mentoring, including serving as the founding director of the UTSW Medical Scientist Training Program (MSTP) in internal medicine, which is now known as the Jean Wilson Society. 
Editing was also a major feature of Jean's academic life. Like many before and after him, Jean was inspired by his tenure as an Editor of the Journal of Clinical Investigation. While this role required an enormous commitment of time and scientific judgement, he noted how much it expanded his already wide knowledge of medicine and reinforced his appreciation of the power of the peer review and editing processes to improve the quality of publications. Jean also served as an editor of Williams Textbook of Endocrinology, the most widely used reference in the field. Not surprisingly, the chapters on sex determination and reproductive endocrinology were masterful and informed generations of physicians throughout the world in the management the complex disorders in these areas. My path intersected with Jean's because of related interests in hormone resistance syndromes. However, more directly, I succeeded him as an editor of Harrison's Principles of Internal Medicine. Wisely, I traveled to Dallas to meet with Jean before taking on this role. His office was overrun with stacks of heavily edited draft chapters and reprints that he used to fact check virtually every statement in his chapters. He was extraordinarily rigorous, but he also had a keen eye for important information and a gift for eloquent prose. I have aspired, perhaps in vain, to emulate his approach and high standards. As he recounted, he took on the editorship because he had witnessed, as a visiting professor in Mexico City, how students throughout the world consumed Harrison's content to improve the health of their patients.

Jean was recognized with numerous awards and leadership roles. Among others, he received the Kober Medal from the Association of American Physicians (AAP); the Fred Conrad Koch Lifetime Achievement Award from the Endocrine Society; the Gregory Pincus Award from the Worcester
Foundation for Experimental Biology; and the Amory Prize from the American Academy of Arts and Sciences (AAAS). He was elected to the American Society for Clinical Investigation (ASCI); the AAP; the National Academy of Sciences, the National Academy of Medicine; the AAAS; and the American Philosophical Society (APS), which he described as having the most interesting programs because of the wide range of topics. He served as president of the Endocrine Society, the ASCI, and the AAP.

Jean was fond of telling the backstory to his discoveries. We are fortunate that his experiences have been captured in multiple interviews $(9,10)$ and in a memoir entitled A Fortunate Man (11). It is notable that he devotes more pages in his memoir to "hobbies and preoccupations" than to his career as a clinician-scientist. His interests were broad and included bird-watching (he identified 719 species), entomology, music, opera, literature, archaeology, bicycling, and ecotourism.

Jean Wilson was a gentle and gracious man, belying his intense work ethic, insatiable curiosity, and exceptionally high standards. He had a gift for narration that made even the most esoteric topics enthralling. Who else could capture the interests of the JCI audience by revealing the mystery of the henny feathering trait of the Sebright bantam chicken? Against the conventional wisdom, he demonstrated that this trait was caused not by a hormone resistance syndrome, but instead by excess aromatization of testosterone to estrogen (12). Or, when medical conferences had numbed the audience, he would reignite the group with a lecture on the life cycle and long-distance migration of monarch butterflies to the Sierra Madre Oriental mountains in Mexico. For Jean, almost every topic was fascinating if you understood it deeply enough. Jean D. Wilson leaves a great legacy of science, writing, and friendships, and we will miss his humor, wisdom, and extraordinary insights into physiology.

Address correspondence to: J. Larry Jameson, Perelman School of Medicine, University of Pennsylvania, 3400 Civic Center Boulevard, Building 421, Philadelphia, Pennsylvania 19104, USA. Email: ljameson@upenn.edu.

1. Braunwald E. A tribute to Donald W. Seldin. J Clin Invest. 2018;128(8):3201-3203.

2. Wilson JD. Localization of the biochemical site of testosterone on protein synthesis in the seminal vesicle of the rat. JClin Invest. 1962;41(1):153-161.

3. Bruchovsky N, Wilson JD. The conversion of testosterone to $5 \alpha$-androstan-17 $\beta$-ol-3-one by rat prostate in vivo and in vitro. $J$ Biol Chem. 1968;243(8):2012-2021.

4. Bruchovsky N, Wilson JD. The intranuclear binding of testosterone and $5 \alpha$-androstan$17 \beta$-ol-3-one by rat prostate. J Biol Chem. 1968;243(22):5953-5960.

5. Siiteri PK, Wilson JD. Dihydrotestosterone in prostatic hypertrophy. I. The formation and content of dihydrotestosterone in the hypertrophic prostate of man. JClin Invest. 1970;49(9):1737-1745.

6. Griffin JE, et al. Dihydrotestosterone binding by cultured human fibroblasts. Comparison of cells from control subjects and from patients with hereditary male pseudohermaphroditism due to androgen resistance. J Clin Invest. 1976;57(5):1342-1351.

7. Walsh PC, et al. Familial incomplete male pseudohermaphroditism, type 2. Decreased dihydrotestosterone formation in pseudovaginal perineoscrotal hypospadias. $\mathrm{N}$ Engl J Med. 1974;291(18):944-949.

8. Wilson JD, et al. Steroid 5 alpha-reductase 2 deficiency. Endocr Rev. 1993;14(5):577-593.

9. Neill US. A conversation with Jean Wilson. JClin Invest. 2012;122(9):3027-3028.

10. Endocrine Society. Oral and Video Histories. https://www.endocrine.org/our-community/ breakthroughs-and-improving-care/sawin-library/ oral-and-video-histories. Accessed July 21, 2021.

11. Wilson JD. The Memoir of a Fortunate Man. CreateSpace Independent Publishing Platform; 2016.

12. George FW, Wilson JD. Pathogenesis of the henny feathering trait in the Sebright bantam chicken. Increased conversion of androgen to estrogen in skin. J Clin Invest. 1980;66(1):57-65. 